\title{
Regularities of the formation of structural fields of daily gas consumption of the regional gas supply system
}

\author{
Deniz Moroz ${ }^{1, *}$, Nadzeya Hruntovich ${ }^{2}$, Nikolay Hruntovich ${ }^{2}$, Aliaksei Kapanski ${ }^{2}$, Larisa Markaryants ${ }^{3}$, and Zumeyra \\ Shakurova ${ }^{4}$ \\ ${ }^{1}$ State Enterprise «Research Institute Belgiprotopgaz», Domashevskij lane,11a, Minsk, Republic of Belarus \\ ${ }^{2}$ Sukhoi State Technical University of Gomel, Prospect Octiabria, 48, 246746, Gomel, Republic of Belarus \\ ${ }^{3}$ Federal State Budgetary Educational Institution of Higher Education «Moscow State Linguistic University» (MSLU), 119034, 38 \\ Ostozhenka St. Moscow \\ ${ }^{4}$ Kazan State Power Engineering University, str. Krasnoselskaya, 51, 420066, Kazan, Russia
}

\begin{abstract}
Daily statistics on the volume of gas consumption and the average daily outdoor air temperature for a six-year period were adopted as an information basis for scientific research with the matter of studying the functioning and developing of the regional gas supply system. For the regional gas supply system, the type of structural fields "daily gas consumption - average daily outdoor air temperature" was determined and their constancy over time was proved. For structural fields, 4 temperature ranges are allocated and a system of characterizing indicators was proposed. The regularities of the formation of daily gas consumption from the average daily outdoor air temperature for the proposed temperature ranges were established, the sensitivity coefficient of the relative change in the daily gas consumption with a relative daily change in the outdoor air temperature was determined. Daily models of the gas consumption dependence on the outdoor air temperature was developed, smoothed by a moving average over 30 days for two temperature regions: 1 - the area of the connected state of the heating system, 2 - the area of the disconnected state of the heating system. The seasonal coefficient of gas consumption was assessed.
\end{abstract}

\section{Introduction}

Today, the modern regional gas supply system (RSGS) is a large (in terms of the number of elements included in it, as well as the number and structure of consumers) and, multi-layered, dynamic technological system [1], the major task of which is to ensure safe and uninterrupted supply of natural and liquefied gas to consumers. Of the entire complex of tasks for the functioning and development of the regional gas supply system, the most acute today are[2-8]:

1. Drawing up applications for the planned volume of gas supplies.

2. Elaboration of projects for the development and reconstruction of gas supply and gas storage systems.

3. Formation of gas tariffs for various groups of consumers, taking into account the profitability of their production.

Moreover, the task of forming applications for the planned volume of gas supplies is currently a priority [3$5,7]$, which is explained by the requirement of Russian gas suppliers to pay at the adjusted tariffs for deviations from the declared volumes of gas consumption. In connection with the designated tasks, it is urgent to study the regularities of the functioning and development of both individual balance groups and the RSGS as a whole.

\section{Research results}

For the first time, daily statistics on the volume of consumed gas, average daily temperature values for 2012-2017 was adopted as an information basis for scientific research on the functioning of the RSGS. To construct the $\left\langle B_{d a y}-t_{d a y}\right\rangle$ fields, the average daily temperature of the outdoor air is converted into Kelvin degrees and is normalized relative to the average annual value. This allowed working only with positive relative values of daily temperature. As a result, the entire possible daily range of outdoor air temperatures in a year is represented by the range from 0.9 to 1.1 r.u. Daily values of gas consumption are also normalized relative to the average annual value. This allowed analyzing and comparing the structural fields $\left." B_{d a y}-t_{d a y}\right\rangle$ in different years [9-13].

For the RSGS, the type of field is defined (Figure 1) with a clear stratification into two temperature regions, determined by the state of the heating system ("enabled" or "disabled") and the overlap of these areas in the zone of an unstable, undefined state of the RSGS (from $0{ }^{\circ} \mathrm{C}$ to $\left.13.6{ }^{\circ} \mathrm{C}\right)$.

* Corresponding author: frostden@ list.ru 
Table 1. Assessment of correlation coefficient $R$ between daily gas consumption in different years of the RSGS.

\begin{tabular}{|l|l|l|l|l|l|l|}
\hline Year & $\mathbf{2 0 1 2}$ & $\mathbf{2 0 1 3}$ & $\mathbf{2 0 1 4}$ & $\mathbf{2 0 1 5}$ & $\mathbf{2 0 1 6}$ & $\mathbf{2 0 1 7}$ \\
\hline $\mathbf{2 0 1 2}$ & 1,000 & 0,894 & 0,919 & 0,901 & 0,928 & 0,913 \\
\hline $\mathbf{2 0 1 3}$ & 0,894 & 1,000 & 0,905 & 0,871 & 0,907 & 0,904 \\
\hline $\mathbf{2 0 1 4}$ & 0,919 & 0,905 & 1,000 & 0,893 & 0,935 & 0,914 \\
\hline $\mathbf{2 0 1 5}$ & 0,901 & 0,871 & 0,893 & 1,000 & 0,916 & 0,903 \\
\hline $\mathbf{2 0 1 6}$ & 0,928 & 0,907 & 0,935 & 0,916 & 1,000 & 0,934 \\
\hline $\mathbf{2 0 1 7}$ & 0,913 & 0,904 & 0,914 & 0,903 & 0,934 & 1,000 \\
\hline
\end{tabular}

The overlay of the structural fields « $B_{d a y}-t_{d a y} »$ of the RSGS for six years showed the stability of the type of field in time (Figure 2). As Figure 2 demonstrates, on the whole, the structural fields « $B_{d a y}-t_{d a y} »$ practically overlap each other over a six-year period. It is proposed to estimate the similarity of fields in different years by the pair correlation coefficient R. It can be done, because the initial annual daily data series on gas consumption are normalized relative to the average annual value of Vt. The use of this technique allows for an assessment of the degree of convergence of the functional dependence of gas consumption in different years. It should be noted that the $\left." B_{d a y}-t_{d a y}\right\rangle$ fields may shift relative to each other, which may be associated with an increase or decrease in gas consumption in the region. In general, such a shift is insignificant over a six-year time interval, since the RSGS as a complex system is characterized by inertia. This means that the system cannot change its state in an abrupt way.

Table 1 demonstrates that between the series of daily values of gas consumption in 2012-2017 in general, there is a high degree of correlation $R>0.9$. However, there is some decrease in $R<0.9$. These are the series of daily gas consumption modes in 2012 and 2013, as well as the modes of $B_{d a y}$ in 2013 and 2014 differ from those of 2015. However, such a slight decrease in the correlation coefficient suggests a high stability and similarity of the type of structural field « $B_{d a y}-t_{d a y} »$ over time.

Four temperature ranges are proposed for the analysis of the structural fields $\left\langle B_{d a y}-t_{d a y}\right\rangle$ (figure 3): first temperature range $0,9 \div 0,97$ r.u. that corresponds to the range of daily average temperature from $-27,3^{\circ} \mathrm{C}$ to $8,2^{\circ} \mathrm{C}$; the second temperature range $0,97 \div 1.00$ r.u. that corresponds to the range of daily average temperature from $-8,2{ }^{\circ} \mathrm{C}$ to $0.0{ }^{\circ} \mathrm{C}$; the third temperature range $1.0 \div 1.05$ r.u., that corresponds to the range of daily average temperature from $0.0^{\circ} \mathrm{C}$ to $+13,6^{\circ} \mathrm{C}$; a fourth temperature range is more than 1.05 r.u., that corresponds to an average daily temperature of more than $+13,6^{\circ} \mathrm{C}$.

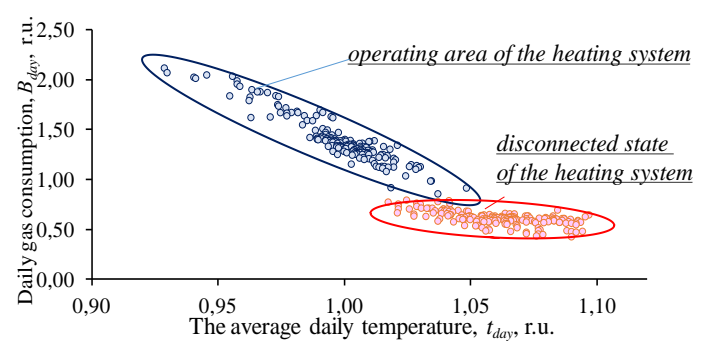

Fig. 1. Structural RSGS field (model).

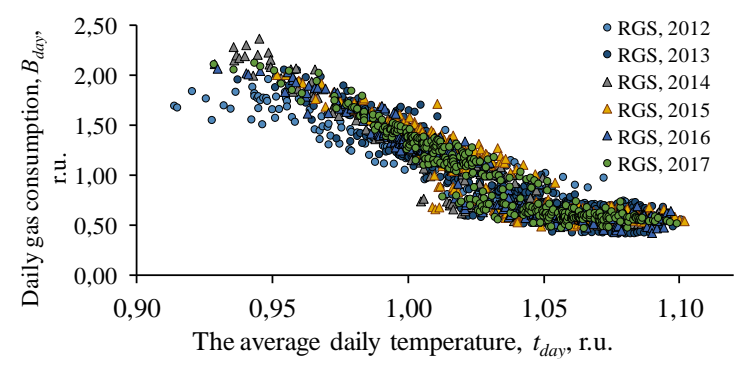

Fig. 2. Overlap of structural fields « $\left.B_{d a y}-t_{d a y}\right\rangle$ RSGS in 20122017.

Table 2 shows the main parameters that characterize the following modes: change in the outdoor air temperature, $t_{d a y}$, expressed in absolute $\left({ }^{\circ} \mathrm{C}\right)$ and in relative (r.u.) units; number of days in the temperature range, $N$, days; standard deviation of gas consumption in the range, $\sigma$, r.u .; coefficient of variation for gas in the temperature range, $V, \%$; sensitivity coefficient of relative change in gas consumption $\Delta B$ with a relative change in the outdoor temperature $\Delta t, K_{s}$, r.u.

The sensitivity coefficient $K_{s}$ is calculated as the ratio of the difference between the maximum and minimum gas consumption $\Delta \mathrm{B}$ in the range to the difference between the maximum and minimum outdoor temperatures $\Delta t$ :

$$
K_{s}=\frac{\left(B_{d a y \text { max }}-B_{d a y \text { min }}\right)}{\left(t_{d a y \text { max }}-t_{d a y \text { man }}\right)}=\frac{\Delta B}{\Delta t}, \text { r.u. }
$$

The following regularities of the formation of daily gas consumption from the average daily outside air temperature for the RSGS were established:

- the first temperature range refers to the lowest outdoor temperature, includes the smallest number of days in the annual interval and characterizes the most severe in terms of temperature and length winter days. So, in 2015 this range included only 7 days with the maximum daily gas consumption of 2.373 r.u., which 
Table 2. Indicators of zones of structural fields $\left.« B_{d a y}-t_{d a y}\right\rangle$ GomRSGS in 2012-2017.

\begin{tabular}{|c|c|c|c|c|}
\hline \multirow{3}{*}{ Indicator name } & \multicolumn{4}{|c|}{ Outdoor air temperature $t_{d a y^{*}}$, r.u. $/{ }^{\circ} \mathrm{C}$} \\
\hline & $<0,97$ r.u. & 0,97-1 r.u. & $1-1,03$ r.u. & $>1,03$ r.u. \\
\hline & $<-8,2^{\circ} \mathrm{C}$ & from $-8,2^{\circ} \mathrm{C}$ to $0^{\circ} \mathrm{C}$ & from $0^{\circ} \mathrm{C}$ to $8^{\circ} \mathrm{C}$ & $>8{ }^{\circ} \mathrm{C}$ \\
\hline \multicolumn{5}{|c|}{2012 г. } \\
\hline Number of days in the range, $N$, day & 42 & 52 & 79 & 193 \\
\hline Gas variation coefficient $V, \%$ & 8,7 & 10,1 & 11,1 & 19,4 \\
\hline Sensitivity coefficient, $K_{s}$ & 9,33 & 19,63 & 22,67 & 10,41 \\
\hline \multicolumn{5}{|c|}{2013 г. } \\
\hline Number of days in the range, $N$, day & 16 & 75 & 79 & 191 \\
\hline Gas variation coefficient $V, \%$ & 8,2 & 12,2 & 21,8 & 22,5 \\
\hline Sensitivity coefficient, $K_{s}$ & 7,16 & 24,03 & 22,67 & 9,80 \\
\hline \multicolumn{5}{|c|}{2014 г. } \\
\hline Number of days in the range, $N$, day & 27 & 42 & 116 & 180 \\
\hline Gas variation coefficient $V, \%$ & 8,7 & 9,4 & 19,1 & 17,7 \\
\hline Sensitivity coefficient, $K_{s}$ & 8,44 & 17,17 & 27,33 & 8,84 \\
\hline \multicolumn{5}{|c|}{2015 г. } \\
\hline Number of days in the range, $N$, day & 7 & 44 & 135 & 179 \\
\hline Gas variation coefficient $V, \%$ & 6,4 & 7,7 & 13,4 & 22,5 \\
\hline Sensitivity coefficient, $K_{s}$ & 4,53 & 18,10 & 35,13 & 11,19 \\
\hline \multicolumn{5}{|c|}{2016 г. } \\
\hline Number of days in the range, $N$, day & 18 & 74 & 97 & 177 \\
\hline Gas variation coefficient $V, \%$ & 7,3 & 9,8 & 16,9 & 12,8 \\
\hline Sensitivity coefficient, $K_{s}$ & 7,07 & 19,57 & 25,23 & 7,99 \\
\hline \multicolumn{5}{|c|}{2017 г. } \\
\hline Number of days in the range, $N$, day & 12 & 55 & 129 & 169 \\
\hline Gas variation coefficient $V, \%$ & 6,3 & 8,7 & 17,3 & 19,2 \\
\hline Sensitivity coefficient, $K_{s}$ & 5,52 & 19,46 & 25,15 & 10,13 \\
\hline
\end{tabular}

corresponded to a "warm" winter. In 2012, this range included 42 days with a maximum daily gas consumption of 1.97 r.u. The first temperature range is characterized by a sufficiently low sensitivity coefficient $K_{s}$ of the relative change in daily gas consumption $\Delta B$ with a relative change in the outdoor air temperature $\Delta t$, which indicates that the system enters the "saturation" zone for maximum gas consumption: boiler heating and technological equipment is designed for a certain maximum load. So, in 2015, $\mathrm{CCH}$ was 4.53 , and its maximum value of 9.33 was noted in 2012;

- the second temperature range from $-8.2{ }^{\circ} \mathrm{C}$ to $0{ }^{\circ} \mathrm{C}$, or 0.97-1 r.u., is distinguished by a higher coefficient of sensitivity of the relative change in gas consumption with a relative change in the outdoor temperature. In 2014, $K_{s}$ was 17.17 . In $2013, K_{s}$ was the peak for the study period - 24.03;

- the third temperature range (from 0.0 to $8.0{ }^{\circ} \mathrm{C}$ ), is unstable in terms of the RSGS gas consumption modes A day of two possible operating modes falls into this range: the connected state of the heating system and its inoperative state. $K_{s}$ for this area is several times higher than $K_{s}$ of the fourth and first areas: $2012-K_{s}$, III / $K_{s}$, IV $=2.2 ; 2013-K_{s}$, III $/ K_{s}$, IV $=2.3 ; 2014-K_{s}$, III $/ K_{s}$, IV $=$ $3.1 ; 2015-K_{s}, \mathrm{III} / K_{s}, \mathrm{IV}=3.1 ; 2016-K_{s}, \mathrm{III} / K_{s}, \mathrm{IV}=3.2$; $2017-K_{s}$, III $/ K_{s}$, IV $=2.5$;

- the fourth temperature range, corresponding to the highest outdoor air temperature, combines the largest number of days of their annual value (from $53 \%$ to
$46 \%$ ). For this range, the coefficient of sensitivity of the daily gas consumption from temperature changes varies from 7.99 to 11.19 .

At the second stage of the research $\left\langle B_{d a y}-t_{d a y}\right\rangle$, the task was to construct daily and average monthly (smoothed over 30 days) models describing the modes with an estimate of the parameters of models of the form: $\quad B_{d a y}=-a \cdot t+b_{\text {cond-const }}$ and $B_{\text {mon.av. }}=-a \cdot t+b_{\text {cond-const }}$ (Figure 3 ). The slope coefficient of the straight line "a", which is the tangent of the angle between the straight line and the positive direction of the temperature axis, is taken as the seasonal coefficient of gas consumption. 
Table 3. Dependence of daily gas consumption on temperature (according to smoothed data) for RSGS.

\begin{tabular}{|c|c|c|c|c|c|c|}
\hline \multirow[b]{2}{*}{ Year } & \multicolumn{3}{|c|}{$\begin{array}{l}\text { Connected mode of the heating system (mode } 1) \\
B_{\text {mon.av. }}=-a \cdot t+b_{\text {cond.-const. }}\end{array}$} & \multicolumn{3}{|c|}{$\begin{array}{l}\text { Disconnected mode of the heating system (mode } 2) B_{\text {mon.av. }} \\
=-a \cdot t+b_{\text {cond.-const. }}\end{array}$} \\
\hline & Equation type & $\begin{array}{c}\text { Seasonal } \\
\text { coefficient, } \\
\text { a }\end{array}$ & $\begin{array}{l}\text { Conditionally } \\
\text { constant gas } \\
\text { consumption } \\
\text { independent of } \\
\text { temperature, } \\
\text { b cond-const.. }\end{array}$ & Equation type & $\begin{array}{c}\text { Seasonal } \\
\text { coefficient, a }\end{array}$ & $\begin{array}{c}\text { Conditionally } \\
\text { constant gas } \\
\text { consumption } \\
\text { independent of } \\
\text { temperature, } b_{\text {cond }} \text { - } \\
\text { const.. }\end{array}$ \\
\hline 2012 & $\begin{aligned} B_{\text {mon.av. }}=-7.102 \cdot t+8.396 \\
\\
R^{2}=0.96\end{aligned}$ & -7.102 & 8.396 & $\begin{aligned} B_{\text {mon.av }}= & =-5.991 \cdot t+7.043 \\
& R^{2}=0.95\end{aligned}$ & -5.991 & 7.043 \\
\hline 2013 & $\begin{array}{c}B_{\text {mon.av }}=-11.54 \cdot t+13.004 \\
R^{2}=0.97\end{array}$ & -11.54 & 13.004 & $\begin{array}{c}B_{\text {mon.av }}=-3.74 \cdot t+4.7187 \\
R^{2}=0.86\end{array}$ & -3.74 & 4.72 \\
\hline 2014 & $\begin{array}{c}B_{\text {mon.av }}=-12.83 \cdot t+14.23 \\
R^{2}=0.996\end{array}$ & -12.83 & 14.23 & $\begin{array}{c}B_{\text {mon.av }}=-4.076 \cdot t+4.929 \\
R^{2}=0.95\end{array}$ & -4.076 & 4.93 \\
\hline 2015 & $\begin{array}{c}B_{\text {mon.av. }}=-12.86 \cdot \mathrm{t}+14.313 \\
R^{2}=0.982\end{array}$ & -12.86 & 14.31 & $\begin{array}{c}B_{\text {mon.av }}=-3.875 \cdot t+4.742 \\
R^{2}=0.923\end{array}$ & -3.875 & 4.74 \\
\hline 2016 & $\begin{array}{c}B_{\text {mon.av }}=-13.15 \cdot t+14.523 \\
R^{2}=0.99\end{array}$ & -13.15 & 14.523 & $\begin{array}{c}B_{\text {mon.av }}=-3.769 \cdot t+4.62 \\
R^{2}=0.92\end{array}$ & -3.769 & 4.62 \\
\hline 2017 & $\begin{array}{c}B_{\text {mon.av }}=-13.744 \cdot t+15.141 \\
R^{2}=0.985\end{array}$ & -13.744 & 15.141 & $\begin{array}{c}B_{\text {mon.av }}=-4.765 \cdot t+5.67 \\
R^{2}=0.967\end{array}$ & -4.765 & 5.67 \\
\hline
\end{tabular}

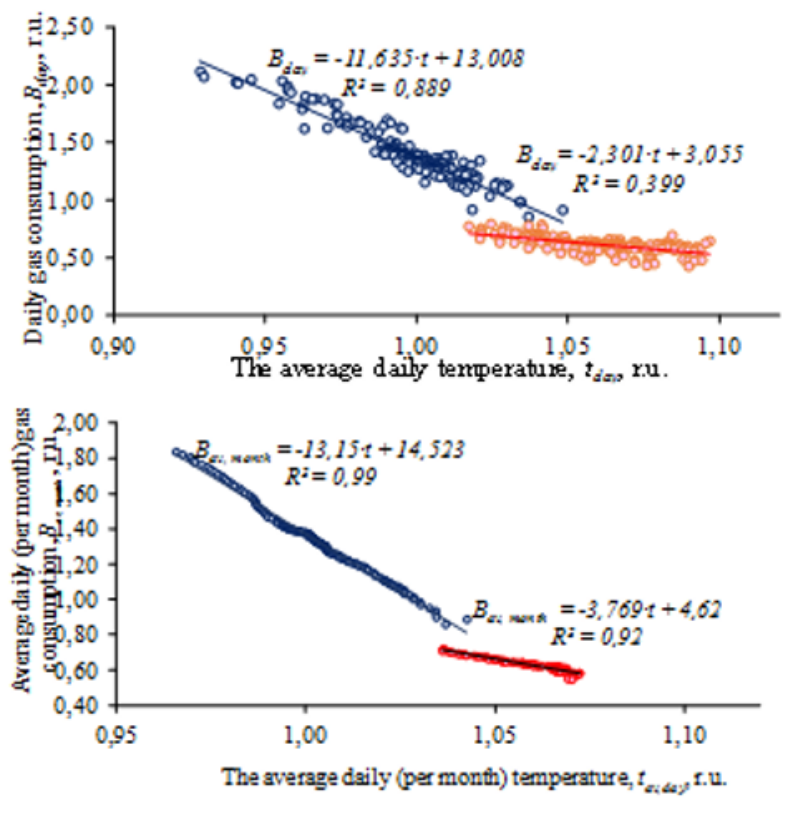

Fig. 3. Results of modeling the daily regimes of the RSGS: 1 models built on the basis of actual daily data; 2 - models built on the basis of data smoothed over 30 days.

As can be seen from Figure 3, the models built on the basis of data smoothed over 30 days have a higher coefficient of determination $R^{2}$, which makes it possible to assert that the quality of the obtained models is quite high. Table 3 demonstrates the models built using smoothed (30 days) data for the RSGS in 2012-2017.

The analysis of the simulation results showed that the models built on the basis of smoothed data (30 days) for two modes for a six-year period have a sufficiently high coefficient of determination $R^{2}>0.9$. An exception is the model of the area of the disconnected state of the heating system for 2013 , where the coefficient $R^{2}=0.86$. In general, the following pattern can be traced:
- models of the heating period for all years have a higher coefficient of determination compared to models of the disconnected state of the heating system. For example, for $2016 R^{2}{ }_{1}=0.99$ and $R^{2}{ }_{2}=0.92$;

- for models of the heating season, the seasonal coefficient «a» varies in the range from -7.102 to 13.744, and there is a steady growth trend of the latter over a six-year period, as well as an increase in the conditionally constant gas consumption, which does not depend on temperature. Over a six-year period, the conditionally constant gas consumption increased from 8.396 to 15.141 , that is, 1.8 times;

- models of the disconnected state of the gas supply system have seasonal coefficients «a» in the range from 3.74 (2013) to -5.991 (2012). Seasonal "a" coefficients of these mode significantly less seasonal coefficients for the heating period models, no definite tendency of their change over the years was revealed. The ratio of the coefficients «a» of the two modes was: $2012-1.2,2013$ - 3.09; 2014 -3.14; 2015 - 3.32; 2016 -3.49; 2017 -2.88.

\section{Conclusions}

1. Research of the modes of daily gas consumption from the outdoor air temperature for the RSGS allowed to establish and prove the stability in time of the structural field with a clear stratification into two temperature regions, determined by the state of the heating system (enabled or disabled) and the overlap of these regions in the unstable, undefined zone of the state of the RSGS (from $0{ }^{\circ} \mathrm{C}$ to $13.6{ }^{\circ} \mathrm{C}$ ). The high degree of similarity of the structural fields in different years was validated by the high coefficient of pair correlation between the series of daily gas consumption in different years.

2. For the established temperature ranges, the following regularities in the formation of the sensitivity coefficient of the relative change in the daily gas consumption with the relative daily change in the outdoor air temperature $K_{s}$ were revealed: 
- for the first temperature range (below $-8.2^{\circ} \mathrm{C}$ ), the lowest sensitivity coefficient $K_{s}=4.53 \div 9.33$ is characteristic, which is explained by the entry of the system into the "saturation" zone in terms of gas consumption (boiler equipment power);

- the highest sensitivity coefficient is noted for the third temperature range $\left(0\right.$ to $\left.8^{\circ} \mathrm{C}\right) \mathrm{Ks}=22.67 \div 35.13$. This temperature range is the most unstable and indeterminate from the point of view of the RSGS modes (enabled or disabled state of the heating system).

3. The developed models of the dependence of the daily gas consumption on the average daily temperature (smoothed over 30 days) for two basic operating modes differ on a high coefficient of determination $\mathrm{R}^{2}=0.86 \div$ 0.996 , which indicates the high quality of the simulation results.

4. The assessment of the seasonal specifics of gas consumption was performed using the slope coefficient of the straight line "a" with the factor "outdoor air temperature". It was identified that the seasonal coefficients of the models of the modes of the disconnected state of the heating system are significantly less than the seasonal coefficients of the models of the modes of the connected state of the heating system.

\section{References}

[1] L. Melentiev, Selected works, Methodology of system researches in power engineering (Moscow, Nauka, 1995) 289 (in Russian)

[2] N. Voropay (Ed.), System research in the energy sector: Retrospective of scientific directions of the SEI - ISEM (Novosibirsk, Nauka, 2010) 686 (in Russian).

[3] N. Ilkevich, Multilevel modeling of the development of gas supply systems (Novosibirsk, Nauka, 2014) 217 (in Russian)

[4] N. Ilkevich, T. Dzyubina, Zh. Kalinina, S. Okuneva, Simulation of the equilibrium of the flows of the cost of supply and demand on natural gas, Pipeline systems of power engineering: methodical and applied problems of mathematical modeling (Novosibirsk, Nauka, 2015) 318-331 (in Russian)

[5] R. Kantjukov, M. Sukharev, V. Meshalkin, R. Gimranov, A. Popov, I. Ryzhenkov, Forecast gas consumption - the basis for making rational decisions on the structure and technological parameters in the design and reconstruction of the gas supply system, Electronic scientific journal Oil and Gas Business 1, 201-221 (2015) (in Russian)

[6] R. Kantjukov, M. Sukharev, V. Meshalkin, R. Gimranov, A. Popov, I. Ryzhenkov (2015) Forecast gas consumption - the basis for making rational decisions on the structure and technological parameters in the design and reconstruction of the gas supply system, Electronic scientific journal Oil and Gas Business 1, 201-221 (2015) (in Russian)

[7] N. Hruntovich, D. Moroz, V. Shalonik, About necessity of study the structure and regularities of the functioning of regional gas supply systems, Energeticheskaja strategija 1, 42-46 (2017) (in Russian)

[8] D.R. Moroz, N.V. Hruntovich, Regional Gas Supply System Considered from the Standpoint of System Analysis and Regularities of its Functioning, Energetika, Proc. CIS Higher Educ. Inst. and Power Eng. Assoc. 61, 4, 359-371 (2018) DOI: $10.21122 / 1029-7448-2018-61-4-359-371$ (in Russian)

[9] D. Moroz, A. Kapanskij, Development of models of gas consumption by structural elements of the regional gas supply system, In the collection: Energy saving and efficiency in technical systems, Materials of the IV International Scientific and Technical Conference of Students, Young Scientists and Specialists, Tambov State Technical University, 416-418 (2017) (in Russian)

[10] R. Kantjukov, M. Sukharev, V. Meshalkin, R. Gimranov, A. Popov, I. Ryzhenkov, Forecast gas consumption - the basis for making rationaldecisions on the structure and technological parameters in the design and reconstruction of thegas supply system, Electronic scientific journal Oil and Gas Business 1, 201-221 (2015)

[11] D. Moroz, Nad. Hruntovich, Nik. Hruntovich, S. Jhukovets, A. Kapansky, L. Dolomanyak, The study of structural fields of daily gas consumption of the balance groups of the regional gas supply system, HSTED-2020, E3S Web of Conferences 178, $01066 \quad$ (2020) DOI: 10.1051/e3sconf/202017801066

[12] F. Peregudov, Introduction to system analysis (Moscow, Vysshaja shkola, 1989) 367 (in Russian)

[13] J.O. Kim, Ch. U. Muller, Factorial, discriminant and cluster analysis [Electronic resource] (Moscow, Finance and statistics, 1989) Available at: http://14000.ru/projects/glass/review.html 